\title{
Justice issues facing family-scale farmers and their laborers in the Northeastern United States
}

\author{
Becca Berkey a* \\ Northeastern University \\ Tania Schusler ${ }^{\mathrm{b}}$ \\ Loyola University Chicago
}

Submitted September 20, 2015 / Revised December 15, 2015, and January 12, 2016 /

Accepted January 12, 2016 / Published online March 21, 2016

Citation: Berkey, B., \& Schusler, T. (2016). Justice issues facing family-scale farmers and their

laborers in the Northeastern United States. Journal of Agriculture, Food Systems, and Community

Development, 6(2), 243-267. http://dx.doi.org/10.5304/jafscd.2016.062.017

Copyright (C) 2016 by New Leaf Associates, Inc.

\begin{abstract}
This study investigates how justice-related issues affect farmers and workers on organic farms in the northeastern United States. At the study's core is an examination of the current context of laborers in organic agriculture in the U.S. Northeast. The study analyzes the results of an online survey of Northeast Organic Farming Association (NOFA) farmer members to gather information about who labors on organic farms in the NOFA network and
\end{abstract}

a * Corresponding author: Becca Berkey, Ph.D., Director of Service-Learning; Research Associate, Northeastern Environmental Justice Research Collaborative; Faculty Affiliate, Northeastern Consortium on Food Systems Sustainability, Health and Equity; Northeastern University; 360 Huntington Avenue, 232YMC; Boston, Massachusetts 02115 USA; +1-617-373-5840; r.berkey@neu.edu

b Tania Schusler, Ph.D., Lecturer and Solutions to Environmental Problems (STEP) Coordinator; Institute of Environmental Sustainability; Loyola University Chicago. what unique justice issues they face. The survey results indicate that most of the farms within the network are small-scale and rely heavily on family members and volunteers for labor. Many of the justice issues related to labor arise from the difficulties these farmers experience achieving financial viability. This study increases understanding of the broader systemic context within which small-scale organic farmers make their commitments and decisions, and it illustrates how the justice-related experiences of both farmers and workers are affected by participation as smallscale organic farms in the larger agricultural system.

\section{Keywords}

organic farming, Northeastern United States, farm labor, small-scale agriculture, family-scale agriculture, family farms, farmworkers

\section{Introduction and Literature Review}

In conventional farming, much justice-related 
research focuses on pesticide use and its effects on worker health (e.g. Moses, 1989; Oxfam America, 2004; Reeves, Katten, \& Guzmán, 2002;

Sologaistoa, 2011), as well as effects of immigration policies and the exploitation of immigrants due to conventional agriculture's reliance on workers from outside the United States (e.g. Stephen, 2003; Taylor, 1992; Wilson \& Portes, 1980). In addition to pesticide exposure and exploitation of immigrant farmworkers, many farmworkers experience a host of other injustices, including substandard housing, that pose further environmental health risks (Arcury, Wiggins, \& Quandt, 2009). Arcury, Wiggins, and Quandt state that in the eastern United States,

Although farmworkers experience high rates of occupational and environmental injury and illness, few programs and regulations have been designed to help reduce these outcomes. Farmworkers and their families in the eastern US seldom have health insurance, and many of them have limited access to health care. The few efforts to reduce farmworker injury and illness seldom consider the culture and educational attainment of farmworkers or the effects of a migratory lifestyle. Long-term consequences of occupational and environmental exposures are virtually unknown. (2009, p. 223)

While pesticide exposure is not a primary concern in organic agriculture, the economic justice issues facing organic farmers and workers in the northeastern U.S. are consistent with many of the challenges faced in conventional agriculture, such as inadequate pay, lack of housing, intense market competition, and health-related problems due to the strenuous nature of the work. However, the reasons for these issues may differ in the organic farming sector. In small-scale organic farming, the issues largely come from a lack of systemic infrastructure within which the farmers themselves can make enough income to support and enact their values of justice and sustainability (Berkey, 2014; Shreck, Getz, \& Feenstra, 2006). Thus small-scale organic agriculture and its farmers and laborers can be considered a population marginalized within the larger political-economic landscape of U.S. agriculture.

Who are these farmers and workers on smallscale organic farms in the northeastern U.S.? It turns out that the answer is not easily uncovered. The U.S. Department of Agriculture (USDA) National Agricultural Statistics Service's (NASS) 2014 Census of Agriculture Organic Production Survey counted 14,048 organic farms and ranches in the United States, totaling 3.67 million acres (1.49 million hectares) of land (USDA NASS, 2015). Of those farms, 12,595 were USDA certified organic and 1,453 were exempt from certification (USDA NASS, 2015). That survey also found that California leads the nation with more than 687,000 acres $(278,000 \mathrm{ha})$ harvested on certified or exempt farms (USDA NASS, 2015). California is followed by Montana, with organic growers harvesting more than 317,000 acres $(128,000$ hectares) (USDA NASS, 2015). Wisconsin, Oregon, and New York follow with more than 200,000 acres $(81,000$ ha) of organic field crops harvested in each (USDA NASS, 2015). According to the 2012 Census of Agriculture, nationally 88 percent of all farms fall under the USDA definition of a small farm, which is an operation that sells less than US $\$ 250,000$ in agricultural products annually (USDA NASS, 2014).

While these reports offer a useful snapshot of organic agriculture nationally, including who works on different types of farms and farm types predominant in different regions of the country, they offer little decisive information that tells the story of farmers and laborers on organic farms in the northeastern United States. With this in mind, we sought to understand who these farmers and laborers are and what justice-related challenges and supports they experience. We conducted this research in collaboration with the Northeast Organic Farming Association (NOFA) to address the question: How do various justice-related issues (including competition in the market, pay, housing, and health) affect farmers and farmworkers on organic farms in the northeastern U.S.?

NOFA is a coalition of seven state chapters whose purpose is "to advocate for and educate on organic and sustainable agriculture, family-scale 
farming and homesteading in rural, suburban and urban areas, agricultural justice and other related policy issues" (NOFA, n.d., para. 1). In conversation with the NOFA Interstate Council, which serves as the board of the NOFA chapters' coalition, we designed a mixed-methods study (Berkey, 2014) to both answer the research question and inform NOFA's program and policy activities. In this paper, we share a portion of that study: The results of a survey of NOFA farmer members, which deepen understanding of who labors on organic farms in the northeastern U.S., the justice-related issues they face, and the politicaleconomic context in which these issues occur. This understanding can help inform coalition-building through organizations like NOFA toward transforming the political-economic landscape of U.S. agriculture and increasing justice for small-scale organic farmers and their workers. We will use the term "Northeast" throughout this article in reference to the northeastern region of the United States, consisting of the seven states in which NOFA operates: Connecticut, Massachusetts, New Hampshire, New Jersey, New York, Rhode Island, and Vermont.

Before continuing, it is essential to clarify the language we use to describe the participants in this study. The research questions were shaped using the terms "farmers" and "farmworkers," who are traditionally presented as distinct categories in the research literature. However, these terms are not mutually exclusive within organic agriculture in the Northeast. We use the term "farmer" to describe the farm owner, although these farmers were themselves also laborers. We use the terms "farmworker," "worker," and "laborer" to describe those working on the farms who did not have ownership responsibilities. These farmworkers also brought valuable experience and knowledge to food production and thus could be considered farmers. Because this research was originally framed as involving "farmers" and "farmworkers" based on the literature, and because we communicated with participants in the study using those terms, we keep this language intact throughout what follows, while recognizing that these terms are not mutually exclusive nor fully capture the nuances of reality.

\section{Applied Research Methods}

\section{Survey Design and Administration}

The survey was co-developed with input from the NOFA Interstate Council, which is one of the groups involved with steering the direction of the organization and implementing any changes (in policy and/or training) seen as necessary based on the findings. Parts of the survey mirrored a survey conducted by the nonprofit organization Florida Organic Growers, which was funded by a Southern Sustainable Agriculture Research and Education grant, offering the possibility of comparable data collected from the two regions.

The survey included 36 items asking questions about the market for organic products, including where farmers sell their products, and issues they encounter (if any) with their major buyers, pay for workers, housing, attitudes toward policies such as Unemployment Insurance thresholds, membership in organizations like NOFA, and benefits farmers derive from those memberships. In addition, the survey asked about farmers' values and practices related to farming organically, such as whether they do so because it is a family tradition, whether they uphold ideals about the environment, etc. The survey enabled us to explore farmers' perceptions of the opportunities, challenges, and pressures related to justice that are specific to organic farms, farmers, and farmworkers. Four open-ended questions inquired about what supports and constraints farmers found in aligning their practices with their beliefs and values, as well as what supports and challenges they faced in the market for their product. To address potential threats to reliability and validity, we aligned survey questions with the conceptual constructs being measured, used practices of good survey design (Dillman, Smyth, \& Christian, 2009), incorporated feedback based on review of a pilot survey by NOFA Interstate Council members to ensure questions were interpreted as intended, and emphasized confidentiality in the survey introduction to encourage farmers to respond honestly.

In describing our data collection methods it is important to clarify the rationale through which sampling decisions were made. The survey population constitutes all of the units to which one 
desires to generalize survey results. While for this survey it would be desirable to generalize the results to all the farmer-members of NOFA and/or organic farmers in the Northeast, it is important to note that the results collected are only representative of those farmers who completed the survey. This is because the sample frame, or the list from which the sample was drawn to represent the survey population, was unavailable to us under the research agreement with NOFA. Thus the sample consisted of all NOFA members and organic farmers who received an invitation to participate and then chose to complete the survey, consistent with a volunteer sampling method. While all members of each NOFA state chapter received the survey through email distribution and information at their annual meetings, the results of the survey are not representative of the whole population but rather describe the opinions and experiences of those who completed it (Dillman et al., 2009).

We administered the survey using SurveyGizmo, an online survey tool, and distributed the link to complete it via a shortened URL (using the tinyurl website) to improve participants' ability to successfully locate it, particularly from printed recruitment materials. The survey opened for responses on January 2, 2013, and closed on March 15, 2013. An invitation to participate was sent electronically on multiple occasions to all members (approximately 1,250 in NOFA through their chapters in the seven Northeast states) using a variety of email lists that reach NOFA farmer members. In addition, we distributed recruitment materials in print at state chapters' annual meetings. Participants had the option of filling out the survey via paper and mailing it back in a postageprovided envelope. Examples of recruitment materials are included in Appendix A, and the survey questions we will discuss in this paper are listed in Appendix B.

\section{Estimated Response Rate}

We received 357 usable survey responses from NOFA farmer members. Because the survey was distributed through various email newsletters and word-of-mouth at conferences and meetings and administered through SurveyGizmo, it is difficult to identify with precision the overall response rate.
However, it is possible to arrive at a rough calculation of the response rate based on estimates given by NOFA of the number of farmer-members to whom the survey was distributed. Per information collected by NOFA's Interstate Council, there are about 5,000 members of NOFA across their network, approximately one-quarter of whom are farmers. Based on these estimates, then, the total number of the population from which this volunteer sample was drawn is 1,250 farmers, indicating a $28.6 \%$ response rate overall.

Although the survey sample was not intended to be representative of all organic farmers in the Northeast, it is useful to have some sense of the extent to which the number of respondents in each state compares to the population of organic farmers in that state. Because data were unavailable from each of the NOFA state chapters on exactly how many farmer members they had, we used publicly available data from the USDA (USDA NASS, 2015), from which we pulled the number of total organic farmers to whom the survey would apply in each of the 9 states sampled (these were the 7 NOFA states with the addition of Pennsylvania and Maine). It is important to note that the USDA numbers represent certified or exempt organic farms and that some NOFA members are not certified although they use organic practices. In addition, the numbers are from the 2014 Organic Survey, so they are likely not the same as our sample given the timeframe of our survey (2012). Therefore, at best these numbers are estimates to gain a sense of the participation rate and where participants fit into the broader population of organic farmers in the Northeast. We did not ask respondent farmers whether their farms were certified organic, so it is difficult to ascertain how representative our sample is of those certified or exempt in each state. In addition, because the survey was distributed throughout multiple channels and those who completed it did so on a volunteer basis, it is possible that those who responded did so because of some particular characteristic such as utilizing good labor practices on their farms, which may have skewed the data.

Table 1 indicates the number of survey respondents and number of certified organic farms in each state. While the survey sample was not a 
probability sample, comparing these figures suggests what proportion of organic farms in each state is captured among survey participants. This comparison shows that in some states, including Rhode Island, Connecticut, Maine, New York, and Massachusetts, the survey respondents, while not a representative sample, reflect between 12 and 29\% of the organic farms in that state. In New Hampshire, respondents could account for upward of $47 \%$ of the organic farms in the state. On the other hand, the percentage of survey respondents in Pennsylvania, Vermont, and New Jersey is so low when compared to the total number of certified and exempt organic farms that it cannot be concluded that they reflect well the experiences and attitudes of the organic farmers within that state.

Because of the nature of this survey and its focus on labor characteristics, constraints, and opportunities, as well as farmer values and involvement in NOFA and other organizations (reported in Berkey, 2014), we did not gather information on farm size or the predominant products on each farm. In hindsight, this is a limitation of our study as we acknowledge that the size of the farm and the products grown, raised, and harvested affects the labor needed on the farm, as well as the conditions in which those workers find themselves. We did gather information on the markets in which respondents sold their products

Table 1. Comparison of Number of NOFA Farmer-Members Responding to Survey and Number of Certified and Exempt Organic Farms in Each State

\begin{tabular}{lccc}
\hline State & $\begin{array}{c}\text { \# Respondents } \\
(\boldsymbol{N = 3 5 7 )}\end{array}$ & $\begin{array}{c}\text { Total \# of Certified } \\
\text { Organic Farms in } \\
\text { State }\end{array}$ & $\begin{array}{c}\text { Percentage } \\
\text { Respondents Based on } \\
\text { Total Number of Organic } \\
\text { Farms* }\end{array}$ \\
\hline Connecticut & 16 & 122 & 13.11 \\
\hline Massachusetts & 32 & 179 & 17.88 \\
\hline Maine & 68 & 517 & 13.15 \\
\hline New Hampshire & 70 & 150 & 46.67 \\
\hline New Jersey & 7 & 87 & 8.05 \\
\hline New York & 118 & 917 & 12.87 \\
\hline Pennsylvania & 18 & 679 & 2.65 \\
\hline Rhode Island & 7 & 24 & 29.17 \\
\hline Vermont & 21 & 542 & 3.87 \\
\hline
\end{tabular}

* Sample was not a probability sample drawn from this population, but a volunteer sample of NOFA farmer-members in each state. as reported in the Results below.

\section{Data Analysis}

Priority areas for data analysis were determined in two ways: (1) alignment with the research questions, and (2) collaborative dialogue with the NOFA Interstate Council. In this paper, we report the results of analysis focused on who works on the farms; information on pay, benefits, and working conditions for workers and their relationship to worker retention; and types of technical assistance sought by NOFA members, including written labor policies. In some instances, data analysis was stratified by state to meet NOFA's organizational needs.

Data were extracted from SurveyGizmo, cleaned, and sorted for analysis, which was primarily descriptive. Correlations were examined between some responses, such as amount of pay and worker retention as well as worker benefits and worker retention. Most analysis was conducted using Excel's descriptive statistics, with the exception of ANOVA and standard deviation calculations, which were conducted using SPSS.

Responses to open-ended questions underwent inductive content analysis (Blackstone, 2012; Glaser \& Strauss, 1967), which consisted of sifting through the responses to identify themes that emerged from the data itself through repeated examination and comparison. This was done by reading and rereading the responses and organizing them into like categories with the aid of Dedoose, a cloud-based qualitative data analysis tool (http://www.dedoose.com). In addition, notes were made about consistent themes that did not answer the question at hand or where respondents responded to the questionsa bout supports and challenges with "none."

\section{Results}

In what follows, we describe the survey results, including 
the types of labor found on these farms, the length of time workers have been on the farms, payroll ranges and benefits for workers, and whether farmers have written labor-related policies. To provide context for interpreting the labor-related results, we begin with data about the markets through which respondents sell their organic products.

\section{Markets}

The survey asked, "Of the total 2012 gross sales of all organic products from your operation (including value-added or processed products) approximately what percentage was marketed through the follow types of sales?" Response options were: Consumer Direct Sales, Direct-to-Retail, and Wholesale Markets. Of the 269 respondents who answered under Consumer Direct Sales, $51.3 \%$ indicated some percentage of their sales as both on-site at the farm and at farmers markets; sales via mail order or Internet came in at the lowest percentage in this category (14.5\%). Of the 238 respondents who answered the question pertaining to their Directto-Retail sales, $37.4 \%$ sell directly to restaurants and caterers, $33.6 \%$ sell directly to natural food stores, and only $4.6 \%$ sell directly to conventional supermarkets. Finally, of the 210 respondents who responded to the question about their distribution in wholesale venues, the highest percentage
$(11.4 \%)$ indicated selling to a distributor, wholesaler, broker, or repacker. Only 3 of the 210 respondents indicated that they distribute to a buyer for conventional supermarket chains. These responses give us some insight to the most important markets for participant farms.

Types of Labor on Farms

All 357 respondents answered the series of questions about the types of labor they use on their farms. As shown in Figure 1, the overwhelming response was "family members," which is not surprising given that the Northeast is known for its small-scale, family farming. As Figure 1 depicts, a large share $(74 \%)$ of farms use the labor of family members, followed by paid employees (43\%), volunteers $(29 \%)$, interns $(21 \%)$, neighbors $(16 \%)$, and customers and/or community supported agriculture (CSA) members (13\%). Note that the categories are not mutually exclusive, meaning that a farmer could check more than one when referring to the same worker (e.g., "Paid employees" could also be "Family members"). For those who answered "other," responses included spouses, developmentally disabled adults, youth needing community service hours, people fulfilling courtmandated community service, and "WWOOFers" (people involved in the World Wide Opportunities on Organic Farms network), among others.

\section{Number of Laborers on Farms by Type}

For all workers, respondents were asked "Please tell us how many people worked on your farm and were [PAID] [NOT PAID] for each category in the 2012 calendar year. 'Year Round' is anyone who is a 12-month employee of your farm and 'Seasonal' applies to anyone working less than that. If no one

\section{Figure 1. Number of Farms by Type of Labor $(N=357)$}

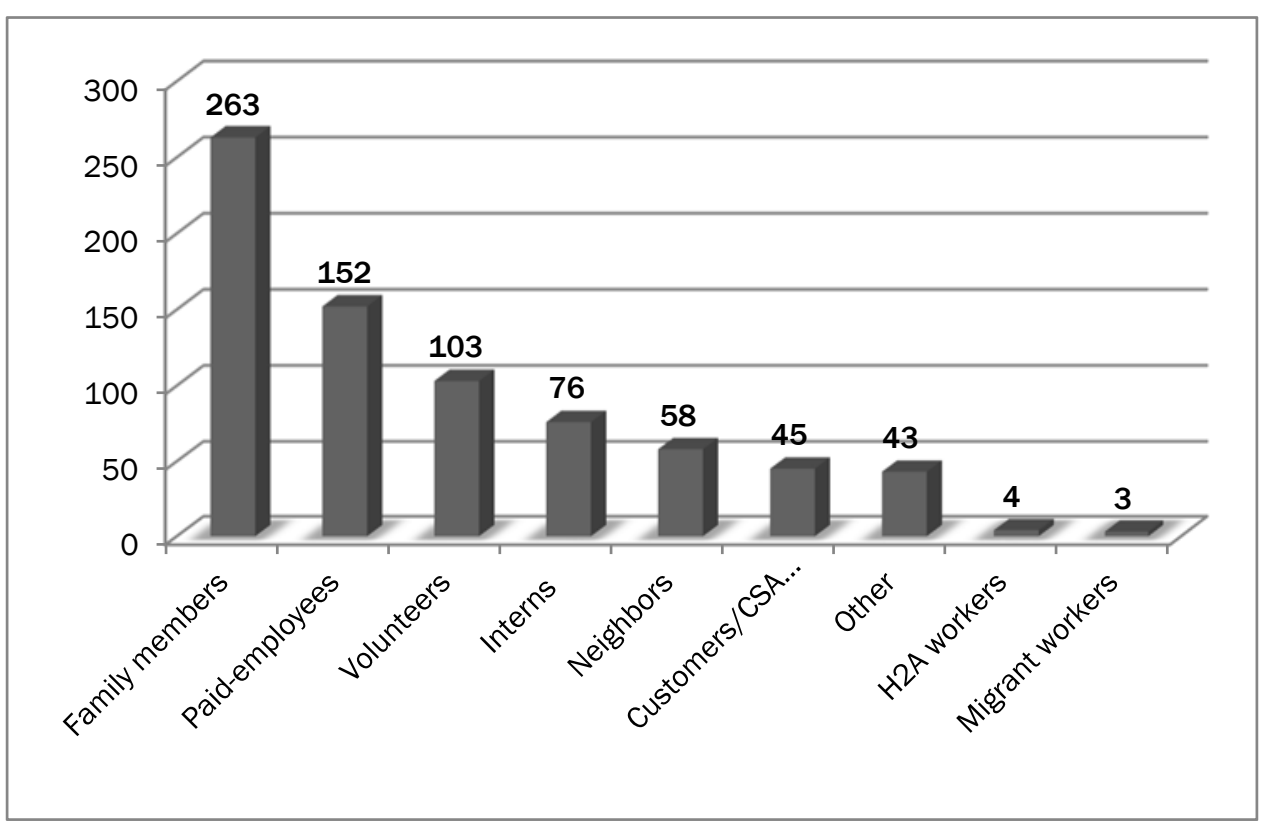


in that category worked on your farm in 2012, please enter 0 ." Table 2 indicates the total number and mean for each type of worker reported. As these tables demonstrate, many farmers depend largely on unpaid workers, namely in the form of seasonal volunteers and customers/CSA members. The survey did not ask how many hours per week or season each type of laborer contributed, the size of the farm, nor the products produced; therefore, comparisons between worker types using these variables is not possible.

\section{Length of Time Working on Farm}

Another important concern with respect to labor is retention. Thus respondents were asked, "What percentage of your workers in 2012 were in their first year working on your farm?" A higher percentage of workers on the farm in their first year would indicate lower retention from the previous year or that the farm was new. Figure 2 summarizes the results of the responses to this question

Table 2. Total Number and Mean Number per Farm of Laborers by Type, Paid and Unpaid Laborers $(N=357)$

\begin{tabular}{|c|c|c|c|c|}
\hline Labor Type and Time on Farm & $\begin{array}{l}\text { Total Paid } \\
\text { Labor }\end{array}$ & $\begin{array}{l}\text { Mean Paid } \\
\text { Labor }\end{array}$ & $\begin{array}{l}\text { Total Unpaid } \\
\text { Labor }\end{array}$ & $\begin{array}{l}\text { Mean Unpaid } \\
\text { Labor }\end{array}$ \\
\hline Full Time, Year Round & 400 & 1.33 & & \\
\hline Full Time, Seasonal & 204 & 0.66 & & \\
\hline Part Time, Year Round & 203 & 0.71 & & \\
\hline Part Time, Seasonal & 373 & 1.12 & & \\
\hline Family Members, Year Round & 156 & 0.54 & 228 & 0.74 \\
\hline Family Members, Seasonal & 134 & 0.48 & 197 & 0.66 \\
\hline Interns/Apprentices, Year Round & 28 & 0.07 & 16 & 0.05 \\
\hline Interns/Apprentices, Seasonal & 105 & 0.33 & 97 & 0.34 \\
\hline Neighbors, Year Round & 11 & 0.04 & 16 & 0.06 \\
\hline Neighbors, Seasonal & 85 & 0.31 & 148 & 0.52 \\
\hline Customers/CSA Members, Year Round & 302 & 1.12 & 247 & 0.86 \\
\hline Customers/CSA Members, Seasonal & 423 & 1.6 & 2,394 & 8.23 \\
\hline Migrant Workers, Year Round & 0 & 0 & 0 & 0 \\
\hline Migrant Workers, Seasonal & 29 & 0.11 & 0 & 0 \\
\hline H-2A* Workers, Year Round & 2 & 0 & 0 & 0 \\
\hline H-2A* Workers, Seasonal & 4 & 0 & 0 & 0 \\
\hline Volunteers, Year Round & & & 507 & 1.73 \\
\hline Volunteers, Seasonal & & & 1,730 & 6.18 \\
\hline TOTAL & 2,459 & & 5,580 & \\
\hline
\end{tabular}

* These are guestworkers who are in the country on a temporary visa called $\mathrm{H}-2 \mathrm{~A}$, which allows them to work in U.S. agriculture (Thompson, 2002). and shows that retention results were bimodal in distribution: nearly half (48\%) of the farms reported that they had less than $10 \%$ new workers, while nearly one-third (32\%) reported that over $40 \%$ of workers in their first year on the farm.

In addition to quantitative data collected through the survey, numerous open-ended questions throughout the survey asked farmers to further explicate their responses. Many participants wrote a great deal of information; the primary themes are summarized below using illustrative quotes. Figure 3 illustrates the five major themes that emerged when participants were asked about their labor challenges in retaining a stable workforce.

As one participant stated, "Being able to provide adequate housing. Being able to provide long-enough seasonal work. Being able to pay a living wage...health care, insurance....all the NOTs are very challenging!" Another farmer pointed out:
Lack of investing knowledge in workers/interns, therefore creating a higher turnover rate seasonally. When interns are treated like day wage laborers (cheap labor, 'slave' labor) they have no incentive to continue working for the farm, instead seeking out better pay, rather than being paid a lower salary with contributing factor being education.

Finally, one of the participants identifying the difficulty of $\mathrm{H}-2 \mathrm{~A}$ paperwork wrote, "We pay a very high premium to government to bring in legal H-2A workers because Americans don't 
stay on the job; don't want to work outdoors; etc."

Some participants used the open-ended responses to provide clarification around items they found confusing or unrepresentative in the survey, while still providing useful perspectives on labor. For example, one participant critiqued the survey in this way by stating:

This section begs for clarification. First, my sole job is the farm, but my husband does bring in an off-farm income. The farm is not his job, but he helps me out when he can. Second, this was not a typical year for us, and we did not hire any teenagers thru our county youth job skills/ employment program. We don't pay those kids, the county does. Third, the kids that I did say helped on farm in 2012 are my neighbors kids. They were not paid, but the survey does not differentiate that in the children section. So, if volunteers/neighbors don't count, don't include my answers. I think the biggest problem I had with my intern is that he did not like doing the weeding and mundane work that is associated with a garden plot. He was interested in the animal husbandry side of it but with $100 \%$ grass fed beef, there is usually only limited time that the animals are interacted with. That would be in the evening when they get moved from paddock to paddock. It was hard to get him to realize the importance of what he was doing even though it was routine and boring.

This farmer identifies some of the same themes identified above, including the availability of reliable and qualified workers.

\section{Payroll Ranges and Benefits to Workers}

Two open-ended questions asked respondents to
Figure 3. Challenges in Retaining a Stable Workforce

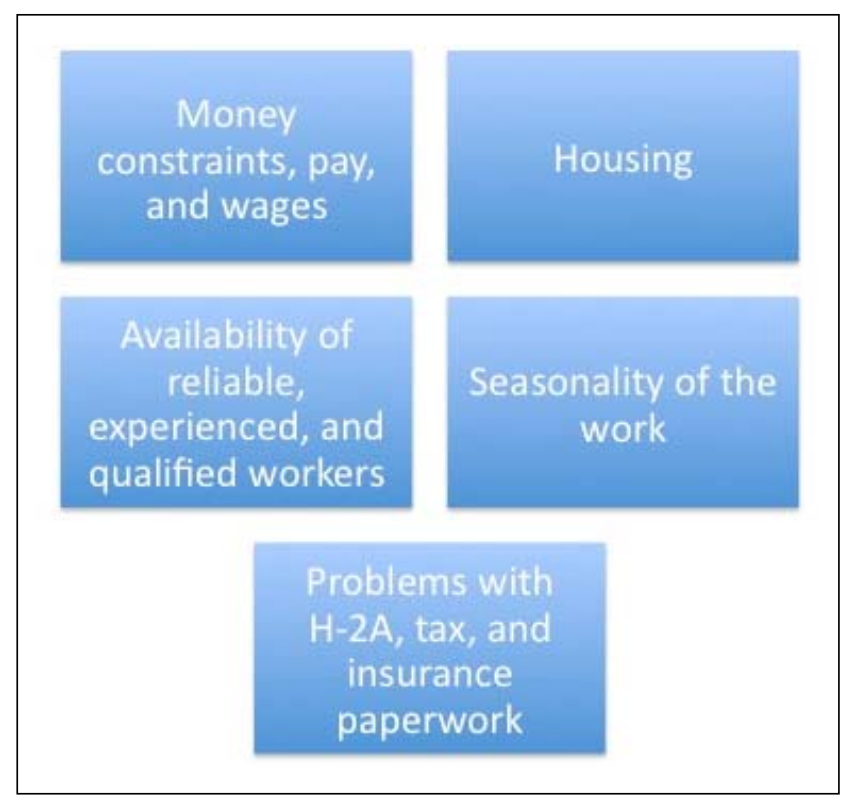

report the amount paid per hour to their lowest and highest paid hourly worker. Some 124 respondents filled out the question asking about the lowest paid hourly worker, and 118 answered regarding their highest paid hourly worker. Several respondents declined to answer this item and instead wrote things such as, "my husband works for love" and "it's us, and we don't know exactly." These answers were not included in the analysis for this item because they could not be quantified for 
Table 3. Mean, Median, and Mode of Lowest- and Highest-Paid Workers, Hourly Rate; $\mathbf{N = 1 2 4}$ for Lowest Paid; $\mathbf{N = 1 1 8}$ for Highest Paid (All in US\$)

\begin{tabular}{lrrrr}
\hline & Mean & Median & Mode & Standard Deviation \\
\hline Lowest-Paid Hourly Worker Rate & 8.92 & 9.00 & 10.00 & 2.84 \\
\hline Highest-Paid Hourly Worker Rate & 11.93 & 11.00 & 10.00 & 4.62 \\
\hline
\end{tabular}

Table 4. Reported Hourly Range, Minimum, and Living Wage by State (All in US\$)

\begin{tabular}{lccc}
\hline State & $\begin{array}{c}\text { Reported Hourly Range with ‘0’ } \\
\text { responses removed (across all } \\
\text { respondents per state, US\$) }\end{array}$ & $\begin{array}{c}\text { Minimum Wage* } \\
\text { (US\$/hour) }\end{array}$ & $\begin{array}{c}\text { Living Wage (1 adult) } \\
\text { (US\$/hour) }\end{array}$ \\
\hline Connecticut & $8.00-15.00$ & 9.15 & 10.68 \\
\hline Maine & $7.25-28.00$ & 7.50 & 8.94 \\
\hline Massachusetts & $5.00-20.00$ & 9.00 & 11.31 \\
\hline New Hampshire & $7.00-16.00$ & $7.25 \ddagger$ & 9.68 \\
\hline New Jersey & $5.00-10.75$ & 8.38 & 11.13 \\
\hline New York & $3.50-25.00$ & 8.75 & 11.50 \\
\hline Rhode Island & $8.00-22.00$ & 9.00 & 9.93 \\
\hline Vermont & $6.50-16.00$ & 9.15 & 9.13 \\
\hline
\end{tabular}

* Source: National Conference of State Legislatures, n.d.

† Source: Glasmeier, n.d.

‡ Federal minimum wage.

an hourly pay range. Table 3 provides the mean, median, and mode for the lowest and highest paid hourly worker. The ranges for these values were from US $\$ 0$ to US $\$ 20$ per hour for the lowest paid hourly worker, and US $\$ 0$ to US $\$ 28$ per hour for the highest paid. A standard deviation of US $\$ 2.84$ for the lowest paid worker and US $\$ 4.62$ for the highest paid indicates more variability for those earning the highest wage. Table 4 provides information about the minimum wage and living wage for each of the states in the network as a point of reference.

Benefits-eligible workers are defined by the federal government as employees who have "worked for a covered employer for at least 12 months, have 1,250 hours of service in the previous 12 months, and if at least 50 employees are employed by the employer within 75 miles" (U.S. Department of Labor, 2013, para. 1). Some 232 respondents reported the number of benefitseligible workers they had during the year 2012; of these, 160 farmers reported having zero benefitseligible workers and 72 reported having 1 or more benefits-eligible workers. The survey itself did not provide the definition above, so participants were left to determine the definition of "benefitseligible" on their own. While the maximum number of benefits eligible workers reported was 150, most farmers reporting having few if any benefitseligible workers, with the mean being 1.89 .

The 72 respondents who reported having 1 or more benefits-eligible workers were asked to identify which benefits they provided to these eligible workers. Table 5 lists the number of responses for each of the benefit types.

The most prevalent benefit provided to benefits-eligible workers by respondent farms is workers compensation insurance, while the least prevalent are maternity/paternity leave, retirement benefits, and time-and-a-half wages for overtime.

Of the 210 participants who responded to the question, "Do you provide housing for your employees?" only $63(30 \%)$ indicated that they do. Of those, $54 \%$ provide housing separate from their homes, $27 \%$ provide in-home housing, $8 \%$ provide housing in a tent or yurt, and 11\% provide "other" housing, with the most popular among those being a mobile home. The number of employees to which responding farmers provide housing varied from 1 or 2 to "all employees." Of the 63 respond- 
ents who provide housing to employees, only $7(11 \%)$ responded "yes" to the question, "Is this housing inspected by local, state or federal authorities?"

\section{Wages, Benefits, and Retention}

We examined the relationship between the workers' pay and retention by converting data about length of time on the farm into a categorical variable, with farms categorized as Low Retention (more than $31 \%$ of workers in their first year on the farm), Medium Retention $(11 \%$ to $30 \%$ of workers in their first year on the farm), and High Retention (less than 10\% of workers in their first year on the farm). Pay rates remained as a continuous numerical variable. We ran a one-way ANOVA to test "the null hypothesis that the sample data were drawn from two or more different groups with the same mean value on a variable of interest" (Welles, 2013, p. 11). In this case, the null hypothesis was that no difference exists between the level of worker retention and the amount of pay. The results illustrate whether the variance within each group is statistically different than the variances between the groups. Finally, statistically significant relationships require a $P$-value of .05 or below. To examine the relationship between retention and the benefits offered to workers, the same categories of High, Medium, and Low Retention farms were used, and benefits were compared using discrete numerical data indicating the number of benefits offered per farm. Table 6 provides information about the comparison variables and $P$-values of those comparisons.

While the relationship between the lowest paid workers and retention was not statistically significant, the relationship between the highest paid workers and retention was $(\mathrm{P}=0.03)$, as was the relationship between worker benefits and retention $(\mathrm{P}=.000)$. Table 7 illustrates these relationships further through multiple comparisons between the retention rate and pay, as well as between retention and the number of benefits.

The statistically significant relationship here
Table 6. Comparison Variables and P-values for ANOVA Tests

\begin{tabular}{lc}
\hline Comparison Variables & $P$-value \\
\hline Lowest Wage Workers and Retention & .419 \\
\hline Highest Wage Workers and Retention & .030 \\
\hline Worker Benefits and Retention & .000 \\
\hline
\end{tabular}

indicates that medium-retention farms are paying an average of US $\$ 2.65$ per hour more than highretention farms. This suggests that factors other than pay also influence workers' decisions to stay with a farm. Several significant relationships were found, with medium-retention farms offering on average 1.79 more benefits than high-retention farms and 1.27 more benefits than low-retention farms. Again, this suggests that factors other than the number of benefits influence workers' decision to stay on a farm.

\section{Written Policies}

Some 85 respondents indicated which written policies they had on their farm: 45 reported that they had written labor policies, 42 responded that they have an emergency plan, and 60 replied that they have a food safety plan. Of the 203 responses to the question, "Would you like help creating written policies?" 51\% responded "No," 40\% responded "Yes," and 9\% indicated "Not Applicable" (because the farmer already has written policies). Table 8 provides information about the respondents to this question by state. 
Journal of Agriculture, Food Systems, and Community Development

ISSN: 2152-0801 online

www.AgDevJournal.com

Table 7. Multiple Comparisons, Retention and Pay and Retention and Benefits

\begin{tabular}{llc}
\hline Retention on Farm & Mean Difference & $P$-value \\
\hline Low Retention & US $\$ 0.18 /$ hour more than high retention & 1.000 \\
\hline Medium Retention & US\$2.65/hour more than high retention & .036 \\
\hline Medium Retention & US\$2.47/hour more than low retention & .078 \\
\hline Low Retention & .52 less benefits than high retention & .152 \\
\hline Medium Retention & 1.79 more benefits than high retention & .000 \\
\hline Medium Retention & 1.27 more benefits than low retention & .002 \\
\hline
\end{tabular}

Table 8. State-by-State Responses to "Would You Like Help Creating Written Policies?"

\begin{tabular}{lrrrcc}
\hline State & Yes & No & N/A & $\begin{array}{c}\text { Did Not Respond } \\
\text { to Item }\end{array}$ \\
\hline Connecticut & 4 & 4 & 0 & 8 \\
\hline Massachusetts & 8 & 9 & 0 & 15 \\
\hline Maine & 12 & 26 & 2 & 28 \\
\hline New Hampshire & 14 & 17 & 3 & 36 \\
\hline New Jersey & 1 & 4 & 1 & 1 \\
\hline New York & 31 & 29 & 9 & 49 \\
\hline Pennsylvania & 5 & 5 & 0 & 8 \\
\hline Rhode Island & 2 & 2 & 1 & 2 \\
\hline Vermont & 3 & 8 & 3 & $\mathbf{1 5 4}$ \\
\hline Total & $\mathbf{8 0}$ & $\mathbf{1 0 4}$ & $\mathbf{1 9}$ & \\
\hline
\end{tabular}

\section{Discussion}

In what follows, we review survey findings and their implications for the research questions, compare our data with publicly available national agricultural data, review the supports and constraints expressed by organic farmers, and finally discuss the opportunities for practice changes for both NOFA and other organizations interested in creating a context for labor justice. It is important to recall that conclusions drawn in this study represent the experiences and perspective of its participants and not all NOFA farmer-members nor all organic farms in the Northeast, although some of these might experience similar conditions.

The survey revealed who labors on these organic farms, pay and benefits for workers, retention, and farmers' labor-related policies. Among organic farmers in the Northeast responding to the survey, the predominant model is a small-scale farm relying heavily on family and volunteer workers, distributing mainly to a local market through farmers' markets, farm stands, and/or community supported agriculture operations
(CSAs). As shown in Figure 1 (above), the largest number of responding farms use the labor of family members, followed by paid employees, volunteers interns, neighbors, and customers and/or CSA members. Many times these worker types were not mutually exclusive, meaning that workers may fall under several categories (such as family member and volunteer). Unpaid laborers make up more than twice the number of paid laborers on these farms (Table 2).
While some farmers choose to involve customers and volunteers in their operations to encourage community education about organic agriculture (Berkey, 2014), it appears that farmers also are using creative approaches to fulfill labor needs for which they lack the financial resources to hire employees.

When it comes to workers' remuneration, amount of pay and the number and types of benefits varied greatly across farms. The median hourly rate reported for the lowest wage earners was roughly equivalent to most states' minimum wage, and that for the highest wage earners equivalent to or slightly above most states' living wage (Tables 3 and 4). However, the range of pay rates varied widely, with the lowest end of the pay range falling below the minimum wage in all 7 states (Table 4). Many responding farmers $(69 \%)$ reported having no benefits-eligible workers. Of those who offered benefits $(31 \%)$, all reported providing workers compensation, as federally mandated. However, the majority did not provide paid vacation, disability insurance, health insurance, paid sick days, time- 
and-a-half wages for overtime, nor retirement benefits (Table 5). Yet $65 \%$ of responding farmers with benefit-eligible workers reported providing an end-of-season bonus. This suggests that farmers are willing to provide benefits but may be unable to afford doing so on a consistent basis. Finally, less than a third of responding farmers reported offering housing for workers. Of those who did, only $11 \%$ reported that housing was inspected by local, state, or federal authorities. Thus the quality of housing provided to workers may vary widely across those farms who do provide it. The ability to provide adequate housing was identified as a key challenge to retaining a stable workforce in our analysis of open-ended responses (along with financial constraints, seasonality of the work, problems with paperwork, and the availability of qualified workers). Although limited data exist to document the current status of farmworker health and safety in the Northeast, the data available indicate problems for farmworkers and their families' health and safety, particularly in the areas of housing, adequate insurance coverage, and protection and training (Arcury et al., 2009). Our data suggest that these concerns also apply to organic farms in the Northeast.

The relationship between pay, benefits, and worker retention (Tables 6 to 10) are somewhat surprising. As described earlier, we used the number of employees in their first year working on the farm to create categories of High $(\leq 10 \%$ workers in first year), Medium (11-30\% workers in first year), and Low Retention ( $\geq 31 \%$ workers in first year) farms. Workers on Medium-Retention farms were paid US $\$ 2.65$ per hour more than workers on High-Retention farms, and workers on MediumRetention farms had more benefits than workers on both Low- (1.79 more) and High-Retention (1.27 more) farms. While one might expect HighRetention farms to have higher pay rates and more benefits, given the reliance upon family members and volunteers for consistent work from year to year, farms with the least number of workers in their first year on the farm (i.e., High Retention) may be staffed by family and volunteers, which would reduce the amount of pay and number of benefits for workers on these farms.

Furthermore, factors beyond pay and benefits can influence worker retention. For example, Jansen (2000) found that quality of labor in organic agriculture in Europe is dependent on four key factors: (1) the content of work (possibilities of defining tasks, acquiring knowledge); (2) labor relations (such as gender differences); (3) working conditions (health and safety, intensity of workload); and (4) the terms of employment (pay, insurance, benefits, etc.). In our broader study (Berkey, 2014), we also found these factors to be important. In addition, quality and retention of labor appeared to be influenced by the consistency of work opportunities and the importance of values as motivation to work on organic farms. In organic farming in the Northeast, the seasonal nature of growing and harvesting left many workers without viable employment during the offseason, making full-time, year-round farm work an impossibility. This sometimes led workers to seek alternative employment elsewhere either permanently or in the off season. In addition, while laborers faced many challenges, they often persevered due to their commitment to organic farming and practices (Berkey, 2014).

Our study found some key similarities and differences between the worker demographics of small-scale organic farms in the Northeast and the broader landscape of U.S. agriculture. The National Agricultural Workers Survey (NAWS) (Carroll, Samardick, Bernard, Gabbard, \& Hernandez, 2005), which describes the demographic and employment characteristics of hired crop farmworkers, found that $75 \%$ of all workers were born in Mexico, and 53 percent of the respondents were not legally authorized to work in the United States. This differs dramatically from our findings, which indicated that very few workers on these smallscale organic farms in the Northeast are from outside the United States. In addition, NAWS found that farmworkers average 33 years of age and are predominantly male. While we did not ask questions specifically about gender and the age of workers in the survey, qualitative data collected in our broader study (Berkey, 2014) indicated concern about an aging population of farmers and workers in organic farming in the Northeast. A majority of the NAWS participants had only one farm employer over the previous twelve months, and many also 
reported that their current job was seasonal. This is consistent with our findings about organic farms in the Northeast and suggests that during a portion of the year workers are either unemployed or in offfarm employment. In the NAWS survey, few participants cited health insurance as a benefit provided by the farm employer. The same trends around pay and benefits from the NAWS survey emerged in our findings: the low provision of health benefits and substandard pay for both workers and farmers themselves.

The 2012 U.S. Census of Agriculture found that $88 \%$ of all farms nationally fall under the USDA small farm definition, because they sell less than US $\$ 250,000$ in agricultural products annually (USDA NASS, 2014). Most farms participating in our study fell under this definition as well. In addition, most of the farms participating in our study reported selling locally at a high rate, and many identified the local market and consumers as one reason they are able to make ends meet. Some mentioned that this is because selling locally aligns with their values, while others indicated the desire to sell to a broader market but lacked a larger infrastructure within which they could distribute their products (Berkey, 2014).

Throughout the course of this study, it became clear that the justice of farmers and workers is inextricably linked on many of the farms that participated in the survey. Therefore, focusing on farmworker justice necessarily requires more broadly understanding the issues that affect not only workers but also the farmers themselves. We began to sum this up in our discussions with NOFA members and others as, "How are these farmers supposed to be thinking about justice for workers when they themselves are barely getting by and/or making a living?" This very question influenced our thinking about how justice is framed, and how the farmers' own livelihoods in turn affect those of their workers. While it is well known that the conventional agricultural system is exploitative of labor, the environment, and consumer health (Gray, 2014; Holmes, 2013; James \& Griswold, 2007; Rothenberg, 1998; Thompson \& Wiggins, 2002), it is interesting to note that the farmers within the NOFA network have the privilege to choose other occupations and yet opt to endure tough working conditions because of a belief and value that this is needed to change the larger system (Berkey, 2014).

Given these characteristics, what supports or constrains organic farmer and farmworker success? Most of the supports that farmers indicated in the survey and qualitative interviews conducted in the broader study (Berkey, 2014) centered on the community of the farm itself, the family and/or members supporting it, the alignment with local consumers who recognized the value of organic agriculture, the network support offered from NOFA chapters, and ongoing educational opportunities about practices that help the business aspect of the farm, such as grant-writing workshops and information on how to obtain other financial supports. The constraints or challenges to creating just labor conditions revolved around navigating the governmental bureaucracy surrounding organic agriculture and farming practices; the sheer cost of operating while lacking a venue for getting a premium price for goods on the market; time; the wherewithal to navigate alternative sources of funding; and finally an inability to retain and sustain a vibrant, educated, and passionate workforce over time (Berkey, 2014).

Many of these constraints are logistical or operational in nature. This indicates that creating just conditions for workers is less about a lack of understanding or commitment to justice on a farmer's part, but rather external factors, such as the inability to access markets and regulatory requirements more suitable to large-scale operations, over which farmers have little if any control. It can be difficult for farms to retain experienced workers from one year to the next because are small-scale and may not be as economically viable as they would like to be, and the work they offer is seasonal. Also, while salary and benefits are important, an increase itself in these in does not equate to a more just or equitable working environment. Other factors such as a sense of community, a value placed on working the land, and other contextual factors are also important (Berkey, 2014).

Some of these constraints stem from the failure of U.S. agricultural policy to provide a system supportive of small-scale, value-driven agriculture. As organic agriculture has evolved in recent 
decades, policy that supports it in many ways has lagged. The farm bill, passed under the official name of the Farm Security and Rural Investment Act of 2002, expired in 2007 when Congress passed an extension to 2012. Congress continued debating and refining a new farm bill while retaining a focus on revitalizing rural areas as well as new goals: "building on momentum of the ag industry and rising farm income; contributing to rural communities and infrastructure; supporting the bioeconomy; protecting nutrition assistance; developing a farm safety net; enhancing conservation and clean energy; promoting markets at home and abroad; and promoting research" (Thomas, 2013, para. 5). While nuanced, the interaction of the farm bill with trade policy as well as the subsidizing of certain crops does not bode well for organic agricultural techniques; since the 2002 legislation was passed it has not resulted in positive labor changes, as the number of rural agricultural jobs continues to drop (James \& Griswold, 2007).

In early 2014, the new farm bill was signed into law. As expected there were some wins for sustainable and organic agriculture. These include investments in beginning farmers, giving them access to land, credit, and training; more funding for research in organic agriculture; provisions making it easier to spend food stamps at local farmers markets; policy ensuring that farmers who receive crop insurance subsidies use natural resources wisely on their farms; and access for farmers with diverse crops and livestock to get insurance tailored to their needs. Also as anticipated, there were some losses as well, some of which are connected to larger losses of public assistance funding, and others specifically affecting farmers of color, rural small business entrepreneurs, the environment (funding for smart resource conservation was cut dramatically), and small- and midsize farmers (there were no subsidy reforms, which means that they remain uncapped and unlimited, ultimately benefiting large, wealthy farms) (National Sustainable Agriculture Coalition, 2014).

In addition to the farm bill's impacts, many larger policies impact labor in U.S. agriculture. One notable policy is the Fair Labor Standards Act of 1938, which excludes agricultural workers and other classes of workers from the protections afforded by the bill. While there have been subsequent amendments to address this (such as the 1966 amendment that required farmers to pay their workers the base minimum wage standard, and the 1983 Migrant and Seasonal Agricultural Workers Protection Act that provides migrant and seasonal farmworkers with increased protections), farmworkers still lack the right guaranteed by the Constitution to organize and advocate for fair and equitable labor practices in their field of work (Anderson, 1989). A tension exists as well between increased standards of protection and wages for farmworkers and the ability of small-scale farmers to meet new thresholds. These are among the challenges to realizing more just working conditions for farmers and workers alike.

This study has implications for future practice within NOFA and other organizations concerned about justice for organic farmers and laborers. NOFA should consider what it can do to ensure training and ongoing employment opportunities for workers. Because of the challenges in recruiting and retaining quality workers, NOFA and other organizations with similar concerns have an opportunity to build organizational infrastructure that connects the right workers with the right farms by identifying not only their skill sets, but also their values. Rather than each farm training its workers independently, NOFA could help develop programs in which farms cooperate to train workers, with farmers contributing knowledge and skills based on their farms' specific assets and needs, developing a more qualified workforce that is adaptable to changes in crop and product yield from year to year due to fluctuations in climate. In addition, NOFA should consider how it can help ensure ongoing employment opportunities for workers when full-year employment cannot be achieved. It might be possible to build alliances with other employers that could use the skills of agricultural workers during their off season.

Because access to health and retirement benefits is a consistent challenge across the network, NOFA can play a role in creating a collective, lower-cost way for farmers and laborers to access benefits. Similarly, NOFA can help reduce the time burden on farmers to do paperwork by providing examples or templates for on-farm written labor and other 
policies (e.g., emergency plan, food safety plan) for the $40 \%$ of respondents who indicated they would like assistance in this regard. Farmers can then adapt these to their specific operational context.

With respect to policy advocacy, it is important for NOFA and organizations focused on justice for laborers within organic agriculture to not only advocate for supportive policies, but also to educate farmers about current issues in policy discussions and to take into consideration farmers' perspectives about how policy changes will affect their operations. For example, a change in labor policy that lowers the revenue threshold at which employers are mandated to provide workers with Unemployment Insurance would improve work conditions for benefits-eligible employees on organic farms, but could degrade the work conditions of farmers who are already financially strapped and struggling to make ends meet. Thus the development of policy agendas by NOFA and similar networks needs to occur in dialogue with farmers and workers to identify creative ways to overcome such tensions. Related to this ongoing dialogue, NOFA should work to educate its members on the positive wins for organic agriculture from the 2014 farm bill and any future legislation affecting organic farmers so that farmers can take advantage of new programs and incentives. Alternately, NOFA should continue to educate its members about the areas where organic farmers lose out due to this bill and other policies so that they can form a more coherent message for future rounds of legislation.

\section{Conclusion}

Most farms in the NOFA network are small-scale farms using organic practices, a population about whose labor practices little specific research has been done. Our findings from a survey of NOFA farmer-members indicate that these farms rely heavily on labor from their families and communities in order to operate. The biggest challenges faced by farmers are financial and having the time and infrastructure necessary to navigate policy and develop markets within which their goods can earn a premium. Additional hurdles include the lack of skilled, trained workers and the means to keep them on board due to both the seasonality of the work and the challenges mentioned previously. Participating farmers report that the challenges facing their workers include the lack of year-round employment, issues with transportation and housing, and the lack of benefits and pay.

These findings highlight the tension between farmers' rationale for small, organic farming and the economic reality within which this scale of agriculture exists. Farmers can name the conditions within which they place their workers and themselves in relation to hours and the nature of work, payment, and benefits, and are transparent about the challenges they face. However, recognizing unjust labor conditions in and of itself does not change the larger system to make farming at this scale more sustainable for business and as an employment option. To further unpack the dynamics of this wicked and complex system, follow-up studies are needed to understand better the reality of this work for the family members, paid laborers, volunteers, community members, and apprentices on these farms in order to inform practical and policy solutions.

In addition, more needs to be known about labor on organic farms in the Northeast and other regions of the United States, as well as globally, given the dearth of publicly available information. While this study is by no means a comprehensive examination of all organic farms in the Northeast, it provides insights into the labor force and related justice issues faced by small-scale organic farmers and farmworkers. Further researching the experiences of these farmers and laborers is essential for informing future policy and practice, not only within NOFA, but also across the Northeast and nationwide. In addition, expanding the geographic scale in a future study in order to include smallscale organic farming across the U.S. would be helpful to compare across regions what is working well to advance justice for organic farmers and their laborers. Doing so could expand and strengthen the network through which organic farmers can connect with and learn from one another toward the development of not only more environmentally sustainable farms, but also economically sustainable businesses that are able to fulfill their values for justice for their owners and employees. 


\section{Acknowledgements}

We would like to thank the Northeast Organic Farming Association (NOFA) for their partnership in this study, especially Elizabeth Henderson, who was our main point of contact, communication, and feedback throughout this study. In addition, we express gratitude to all of the farmers who participated in the survey. Finally, we would like to thank Dr. Steve Chase and Dr. Joseph Siry, who provided invaluable insight and perspective to this project.

\section{References}

Anderson, P. M. (1989). The agricultural employee exemption from the Fair Labor Standards Act of 1938. Hamline Law Review, 12, 649-668.

Arcury, T. A., Wiggins, M. F., \& Quandt, S. A. (2009). Conclusions: An agenda for farmworker social justice in the eastern United States. In S. A. Quandt \& T. A. Arcury (Eds.), Latino farmworkers in the Eastern United States (pp. 221-233). New York: Springer. http://dx.doi.org/10.1007/978-0-387$\underline{88347-2 \quad 10}$

Berkey, R. E. (2014). Just farming: An environmental justice perspective on the capacity of grassroots organizations to support the rights of organic farmers and laborers (Doctoral dissertation). Antioch University New England, Keene, New Hampshire. Retrieved from https://etd.ohiolink.edu/ap/10?216504457693527:: NO:10:P10_ETD_SUBID:98613

Blackstone, A. (2012). Principles of sociological inquiry: Qualitative and quantitative methods, v. 1.0. Washington, D.C.: Flat World Knowledge. Retrieved from http://catalog.flatworldknowledge.com/catalog/ed itions/blackstone-principles-of-sociological-inquiryqualitative-and-quantitative-methods-1-0

Carroll, D., Samardick, R. M., Bernard, S., Gabbard, S., \& Hernandez, T. (2005). Findings from the National Agricultural Workers Survey (NAWS) 2001-2002: A demographic profile of United States farm workers (Research Report No. 9). Retrieved from https://www.doleta.gov/agworker/report9/naws rpt9.pdf

Dillman, D. A., Smyth, J. D., \& Christian, L. M. (2008). Internet, mail, and mixed-mode surveys: The tailored design method ( $3^{\text {rd }}$ ed.). Hoboken, New Jersey: John Wiley $\&$ Sons.

Glaser, B. G., \& Strauss, A. L. (1967). The discovery of grounded theory: Strategies for qualitative research. Chicago: Aldine Publishing Company.
Glasmeier, A. K. (n.d.). Living wage calculator. Retrieved August 30, 2015, from http://livingwage.mit.edu/

Gray, M. (2014). Labor and the locavore: The making of a comprehensive food ethic. Berkeley: University of California Press. Retrieved from http:/ / librarytitles.ebrary.com/Doc?id=10779332

Holmes, S. M. (2013). Fresh fruit, broken bodies: Migrant farmworkers in the United States. Berkeley: University of California Press.

James, S., \& Griswold, D. (2007, April 16). Freeing the farm: A farm bill for all Americans (Trade Bill Analysis No. 34). Retrieved from the Cato Institute website, November 23, 2013, at http://www.cato.org/ publications/trade-policy-analysis/freeing-farmfarm-bill-all-americans

Jansen, K. (2000). Labour, livelihoods and the quality of life in organic agriculture in Europe. Biological Agriculture \& Horticulture, 17(3), 247-278. http://doi.org/10.1080/01448765.2000.9754845

Moses, M. (1989). Pesticide-related health problems and farmworkers. American Association of Occupational Health Nurses Journal, 37(3), 115-130.

National Conference of State Legislatures. (n.d.). State minimum wages | 2015 minimum wage by state.

Retrieved August 30, 2015; archived at https://web.archive.org/web/20150828065625/ http://www.ncsl.org/research/labor-andemployment/state-minimum-wage-chart.aspx

National Sustainable Agriculture Coalition. (2014, January 31). What is in the 2014 farm bill for sustainable farms and food systems? [Blog post]. Retrieved from http://sustainableagriculture.net/ blog/2014-farm-bill-outcomes/

Northeast Organic Farming Association [NOFA]. (n.d.). Who we are? Northeast Organic Farming Association. http://www.nofa.org/whoweare.php

Oxfam America. (2004). Like machines in the fields: Workers without rights in American agriculture. Retrieved November 11, 2013, from http://www.oxfamamerica.org/publications/likemachines-in-the-fields-workers-without-rights-inamerican-agriculture

Reeves, M., Katten, A., \& Guzmán, M. (2002). Fields of poison 2002: California farmworkers and pesticides. San Francisco: Californians for Pesticide Reform. Retrieved from http://www.panna.org/sites/ default/files/FieldsofPoison2002Eng.pdf 
Rothenberg, D. (1998). With these hands: The hidden world of migrant farmworkers today. New York: Harcourt Brace.

Shreck, A., Getz, C., \& Feenstra, G. (2006). Social sustainability, farm labor, and organic agriculture: Findings from an exploratory analysis. Agriculture and Human Values, 23(4), 439-449. http://dx.doi.org/10.1007/s10460-006-9016-2

Sologaistoa, E. (2011). Farmworkers in the Southeast: Alabama, Florida, Georgia, Mississippi. Tallahassee, Florida: Author. Retrieved from http://www.fachc.org/pdf/Farmworkers $\% 20$ in $\% 2$ 0the $\% 20$ Southeast.pdf

Stephen, L. (2003). Cultural citizenship and labor rights for Oregon farmworkers: The case of Pineros y Campesinos Unidos del Nordoeste (PCUN). Human Organization, 62(1), 27-38. http://dx.doi.org/10.17730/humo.62.1.004w5xyrq $\underline{1 \mathrm{dlxn} 68}$

Taylor, J. E. (1992). Earnings and mobility of legal and illegal immigrant workers in agriculture. American Journal of Agricultural Economics, 74(4), 889-896. http://doi.org/10.2307/1243186

Thomas, J. (2013, November 22). White House report quantifies farm bill's economic impact [Blog post]. Retrieved from the Farm Futures website, November 23, 2013, at http:/ / farmfutures.com/ story-white-house-report-quantifies-farm-billseconomic-impact-0-105233
Thompson, C. D. (2002). Introduction. In The human cost of food: Farmworkers' lives, labor, and advocacy (pp. 219). Austin: University of Texas Press.

Thompson, C. D., \& Wiggins, M. F. (2002). The human cost of food: Farmworkers' lives, labor, and advocacy (1st ed.). Austin: University of Texas Press.

U.S. Department of Agriculture [USDA], National Agricultural Statistics Service [NASS]. (2014). 2012 Census of Agriculture: United States summary and state data (Volume 1, Geographic Area Series, Part 51). Retrieved from http://www.agcensus.usda.gov/ Publications/2012/Full Report/Volume 1, Chapter 1 US/usv1.pdf

USDA NASS. (2015). Organic Production Survey (2014) (Volume 3, Special Studies, Part 4). Retrieved from http://www.agcensus.usda.gov/Publications/2012 LOnline Resources/Organics/ORGANICS.pdf

U.S. Department of Labor. (2013, February). Employee rights and responsibilities under the Family and Medical Leave Act. Retrieved from http://www.dol.gov/ whd/regs/compliance/posters/fmlaen.pdf

Welles, B. (2013, July). Testing for Difference in SPSS [Class handout]. Boston: Department of Communication Studies, Northeastern University.

Wilson, K. L., \& Portes, A. (1980). Immigrant enclaves: An analysis of the labor market experiences of Cubans in Miami. American Journal of Sociology, 86(2), 295-319. http://dx.doi.org/10.1086/227240 


\section{Appendix A. Examples of Recruitment Materials}

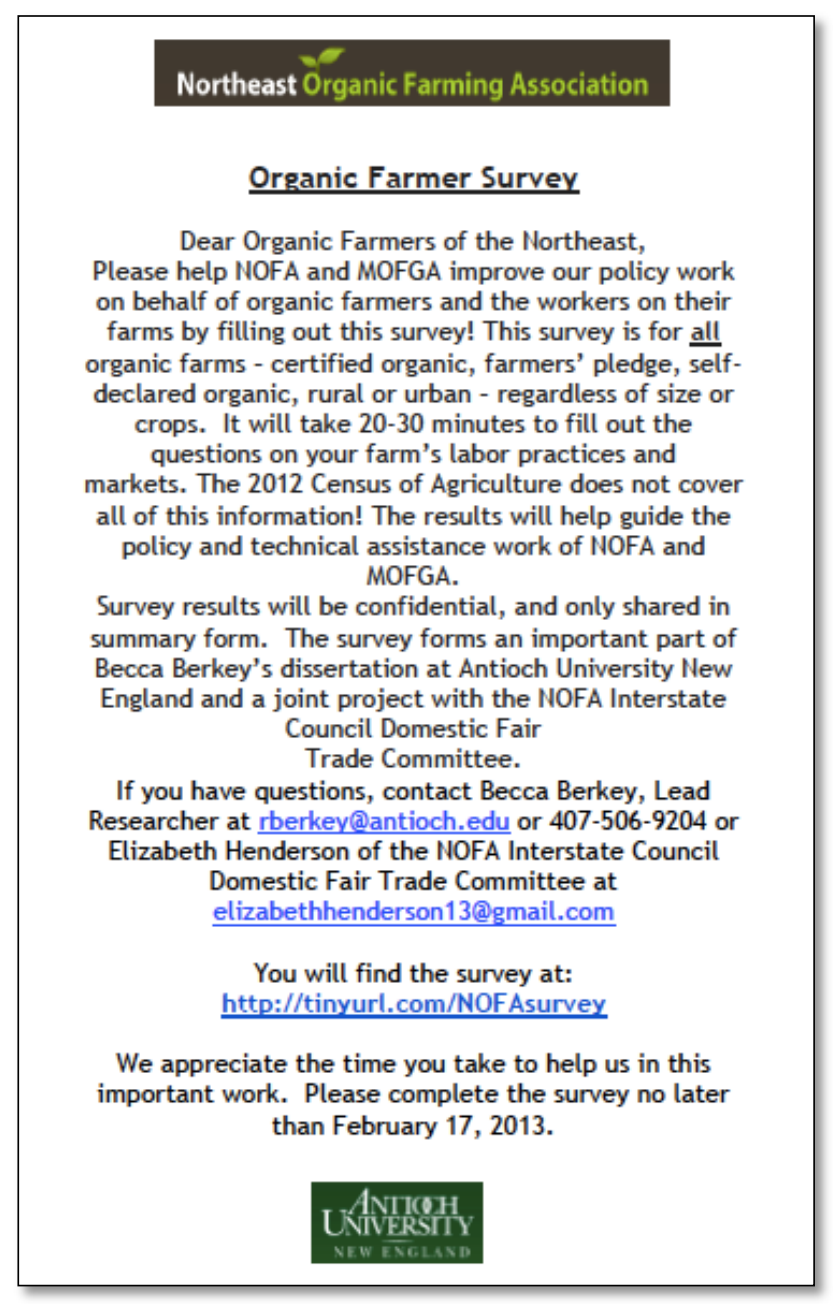

Flier distributed to organic farmers at NOFA statewide annual meetings January-March, 2013. 


\section{Take a Few Minutes to Complete the MOFGA/NOFA Farm Questionnaire}

MOFGA and the Northeast Organic Farming

Association invite organic farmers to complete a

survey that will help support farms and farm workers

in the Northeast. This survey is meant for all organic

farms - certified organic, farmers pledge, or

self-declared organic, rural or urban - regardless of

size or crops. No one has ever collected this information before! The results will help guide the policy and technical assistance work of NOFA and MOFGA. Please fill out the survey at: http://tinyurl.com

¿NOFAsurvey.

MOFGA's (Maine) appeal to farmers.

\begin{tabular}{|c|c|}
\hline \multicolumn{2}{|l|}{ nofanh header border } \\
\hline New Hampshire Farmers! & $\begin{array}{l}\text { Surprisel } \\
\text { winter }\end{array}$ \\
\hline $\begin{array}{l}\text { Please take } 20-30 \text { minutes of your time for this survey on your } \\
\text { farm's labor practices and markets. }\end{array}$ & $\begin{array}{l}\text { Conference Early } \\
\text { Bird Registration }\end{array}$ \\
\hline $\begin{array}{l}\text { http://www.surveygizmo.com/s3/1110707/Farmer-Survey- } \\
\text { NOFA-amp-Antioch-Study }\end{array}$ & $\begin{array}{l}\text { Discount } \\
\text { Extended to }\end{array}$ \\
\hline $\begin{array}{l}\text { This survey is meant for all organic farms - certified organic, } \\
\text { farmers pledge, or self-declared organic, rural or urban - } \\
\text { regardless of size or crops. }\end{array}$ & February 8th \\
\hline $\begin{array}{l}\text { The survey results will be confidential, and only shared in summary } \\
\text { form. The survey is an important part of the research for Becca } \\
\text { Berkey's dissertation at Antioch College and is a joint project with }\end{array}$ & Register Now \\
\hline the NOFA Interstate Council Policy Committee and MOFGA. & Quick Links \\
\hline $\begin{array}{l}\text { No one has ever collected this information before! The results will } \\
\text { help guide the policy and technical assistance work of NOFA and } \\
\text { MOFGA. }\end{array}$ & $\begin{array}{l}\text { Contact } \\
\text { Become a Member }\end{array}$ \\
\hline Thank you, & \\
\hline NOFA-NH Board of Directors & \\
\hline
\end{tabular}

\section{NOFA-New Hampshire's appeal to farmers.}




\section{Business Tools}

\section{Northeast Organic Farmer Survey Attention ORGANIC farmers!}

This January \& February, all NOFA chapters and MOFGA are circulating this survey to farmer members here. Please take 20-30 minutes of your precious wintertime for this survey on your farm's labor practices and markets. The purpose of this study is to find out how pay, housing, health and the prices farmers receive affect farmers and farm workers. This survey is meant for all organic farms - certified organic, farmers' pledge, or self-declared organic, rural or urban - regardless of size or crops. Results will be confidential and shared only in summary form. The survey forms an important part of the research for Becca Berkey's dissertation at Antioch College and is a joint project with the NOFA Interstate Council Policy Committee. No one has ever collected this information before! Results will guide policy and technical assistance work of NOFA and MOFGA. For more information, email Elizabeth Henderson.

\section{NOFA-Rhode Island's appeal to farmers.}

\section{Northeast Organic Farmer Survey \\ Attention ORGANIC farmers! All NOFA chapters and MOFGA are circulating a survey to farmer members. Please plan to take 20-30 minutes of your precious winter time to take this survey on your farm's labor practices and markets.}

The purpose of this study is to find out how things like pay, housing, health, and the prices farmers receive affect farmers and farmworkers. This survey is meant for all organic farms - certified organic, farmers' pledge, or self-declared organic, rural or urban - regardless of size or crops.

The survey results will be confidential, and only shared in summary form. The survey forms an important part of the research for Becca Berkey's dissertation at Antioch College and is a joint project with the NOFA Interstate Council Policy Committee. No one has ever collected this information before! The results will help guide the policy and technical assistance work of NOFA and MOFGA.

Click here to take the survey, and thank you for your time!

\section{NOFA-Vermont's appeal to farmers.}




\section{Appendix B. Farmer Survey}

The survey may also be viewed in its online format at http://www.surveygizmo.com/s3/1110707/FarmerSurvey-NOFA-amp-Antioch-Study

\section{Introduction}

Member Farmer Survey

Research conducted by the Northeast Organic Farming Association and Becca Berkey, PhD Candidate at Antioch University New England

This survey is being distributed to the farmer-members of the Northeast Organic Farming Association (NOFA), covering 7 states in the northeast with the addition of the Maine Organic Farmers and Gardeners Association (MOFGA). The original idea and identification of need for the survey generated in the Labor and Trade Working Group of the Northeast Sustainable Agriculture Working Group (NESAWG), of which NOFA is a member. We are doing a study about issues that affect farmers and farmworkers on organic farms in the Northeast. You are invited to be a part of this study by participating in this survey, because your farm is a member in the Northeast Organic Farming Association (NOFA).

The purpose of this study is to find out how things like pay, housing, and health affect farmers and farmworkers. Our focus is on organic farms in the northeast. We are asking farmers and farmworkers to tell us about their experiences. We want to know more about:

- Issues that farmworkers and farmers care about;

- How these compare to conventional agriculture;

- How NOFA can better support farmers and farmworkers.

From this study, NOFA hopes to learn how to help improve the lives of farmers and farmworkers. Also, Becca Berkey is doing this study as part of a degree program at Antioch University New England.

Please complete this questionnaire online at your earliest convenience. Should you prefer to complete it via paper, please contact the researcher, Becca Berkey, at rberkey@antioch.edu, and she will provide you with a hard copy and a postage-paid envelope in which to return it.

Your participation in this survey is voluntary, but we sincerely hope you will take 20-30 minutes to answer our questions. You can opt out of the survey at any time, and will be asked to provide your contact information at the end only if you feel comfortable doing so. If you complete the survey, it means that you would like to be a volunteer in this research study. If you decline, it will not affect your relationship with NOFA or Antioch University New England. The information you provide will remain strictly confidential and will never be associated with your name or shared with any government or private agencies. Only Becca Berkey will have access to the complete survey data. Elizabeth Henderson and Louis Battalen of NOFA will have access to survey data without your name or the farm you represent. We will not identify you in reports or talks about this study. If you ask us, we will let you comment on reports from this study before they are published.

Please ask any questions you have now or in the future. The lead researcher is Becca Berkey of Antioch University New England. You may call her at 407-506-9204 or e-mail her at rberkey@antioch.edu. If you have any questions about your rights as a research participant, you may contact Dr. Katherine Clarke, kclarke@antioch.edu, Chair of the Antioch University New England Institutional Review Board, or Dr. Stephen Neun, sneun@antioch.edu, Vice President of Academic Affairs at Antioch University New England.

Thank you again for taking the time to respond! 


\section{Section 1, Information about Workers}

In which state is your farm located?
a. Connecticut
b. Maine
c. Massachusetts
d. New Hampshire
e. New Jersey
f. New York
g. Rhode Island
h. Vermont

Who works on your farm? Please check all that apply.

- Family members

- Interns

- Neighbors

- Customers/CSA members

- Volunteers

- Paid employees

- Migrant workers

- $\mathrm{H}-2 \mathrm{~A}$ workers

- Other

Please describe:

Paid Workers: Please tell us how many people worked on your farm and got PAID for each category in the 2012 calendar year. 'Year Round' is anyone who is a 12-month employee of your farm and 'Seasonal' applies to anyone working less than that. If no one in that category worked on your farm in 2012, please enter 0 . Use the 'Tab' button on your keyboard to move from one field to the next.

\begin{tabular}{|l|l|l|}
\hline \multicolumn{1}{|c|}{ Category } & Year Round & Seasonal \\
\hline \# Full-Time & & \\
\hline \# Part-Time & & \\
\hline \# of Family Members & & \\
\hline \# of Interns/Apprentices & & \\
\hline \# of Neighbors & & \\
\hline \# of Customers/CSA Members & & \\
\hline \# of Migrant Workers & & \\
\hline \# of H-2A Workers & & \\
\hline Other (please describe) & & \\
\hline
\end{tabular}

Unpaid Workers: Please tell us how many people worked on your farm and were NOT PAID for each category in the 2012 calendar year. 'Year Round' is anyone who is a 12-month employee of your farm and 'Seasonal' applies to anyone working less than that. If no one in that category worked on your farm in 2012, please enter 0 . Use the 'Tab' button on your keyboard to move from one field to the next.

\begin{tabular}{|l|l|l|}
\hline \multicolumn{1}{|c|}{ Category } & Year Round & Seasonal \\
\hline \# of Family Members & & \\
\hline \# of Interns/Apprentices & & \\
\hline \# of Neighbors & & \\
\hline \# of Customers/CSA Members & & \\
\hline \# of Volunteers & & \\
\hline \# of Migrant Workers & & \\
\hline \# of H-2A Workers & & \\
\hline Other (please describe) & & \\
\hline
\end{tabular}


What percentage of your workers in 2012 were in their first year working on your farm?

$0-10 \%$

$11-20 \%$

$21-30 \%$

$31-40 \%$

$>40 \%$

What are some of the labor challenges you face in retaining a stable work force, if any?

\section{Section 1A: Your Priorities in Farming}

[This section deleted because we are not discussing the results in this paper.]

\section{Section 1B: Experiences and Practices in Selling Farm Products}

Please describe your relationships and experiences with your buyers. In this section we would like to know about constraints you face regarding your ability to make a fair living by farming/ranching and the beneficial practices you engage in with buyers.

Of the total 2012 gross sales of all organic products from your operation (including value-added or processed products) approximately what percentage was marketed through the follow types of sales? (please fill in approximate \%, noting that the cumulative total from all three areas should equal 100\%)

\begin{tabular}{|c|c|}
\hline Products Sold Through: & $\begin{array}{c}\% \text { of Total } 2012 \text { Gross } \\
\text { Organic Sales }\end{array}$ \\
\hline \multicolumn{2}{|l|}{ Consumer Direct Sales } \\
\hline a. $\quad$ On-site (e.g., farm stand, u-pick) & $\%$ \\
\hline b. $\quad$ Farmer's market & $\%$ \\
\hline c. Community Supported Agriculture (CSA) shares & $\%$ \\
\hline d. Mail order or internet & $\%$ \\
\hline $\begin{array}{ll}\text { e. } & \text { Other consumer direct (please specify) }\end{array}$ & $\%$ \\
\hline \multicolumn{2}{|l|}{ Direct-to-Retail } \\
\hline f. $\quad$ Natural food stores (cooperatives and supermarkets) & $\%$ \\
\hline g. $\quad$ Conventional supermarkets & $\%$ \\
\hline h. Restaurants or caterers & $\%$ \\
\hline Other direct to retail (please specify) & $\%$ \\
\hline \multicolumn{2}{|l|}{ Wholesale Markets } \\
\hline j. $\quad$ Natural food store chain buyer & $\%$ \\
\hline k. Conventional supermarket chain buyer & $\%$ \\
\hline I. $\quad$ Processor, mill, or packer & $\%$ \\
\hline m. Distributor, wholesaler, broker, or repacker & $\%$ \\
\hline n. Grower cooperative & $\%$ \\
\hline o. Other wholesale (please specify) & $\%$ \\
\hline
\end{tabular}

\section{Section 2, Information about Wages and Benefits}

How many benefits-eligible workers (regular and long-time temporary full and part time workers) did you employ in 2012?

Which of the following monetary benefits did you provide these workers? Check all that apply.

- Unemployment insurance

- Workers compensation insurance

- Disability insurance

- Health insurance 
- Retirement benefits

- Paid sick days

- $\quad$ End of season bonus

- Housing discount

- Maternity/paternity leave

- Time and a half for overtime-please indicate the \# of hours worked in a week after which the worker receives overtime pay:

- Paid vacation days-please indicate the number of days annually per worker:

- Other (please describe)

If you provide bonuses to workers, how do you decide how much to pay and who receives one?

What rate do you pay your lowest-earning hourly worker?

What rate do you pay your highest-earning hourly worker?

Please check the appropriate columns based on your labor practices.

\begin{tabular}{|l|l|l|}
\hline \multicolumn{1}{|c|}{ Labor Practice } & Yes & No \\
\hline Do you have written contracts with your employees? & & \\
\hline Do you provide pay stubs each time you pay? & & \\
\hline Do you display legally required postings at your farm? & & \\
\hline Do you have a seniority policy? & & \\
\hline Does seniority play a role in lay offs or rehiring? & & \\
\hline If you lay workers off at the end of a season, do you hire them back the next year? & \\
\hline
\end{tabular}

b. Do you provide housing?

- Yes

- $\quad$ No (if 'No', skip to question 26)

c. For how many employees do you provide housing?

d. Where do you provide housing?

- In my home

- In separate housing

- In a tent/yurt

- Other

Please describe:

e. Is this housing inspected by local, state, or federal authorities?

- Yes

- No

f. What training do you provide to employees? Please check all that apply.

- Safety

- Health

- Food safety

- Worker protection standard (WPS)

- Legal rights

- Other

Please describe:

g. Which of the following do you have on your farm? Check all that apply.

- Written labor policies

- Emergency plan

- Food safety plan 
Journal of Agriculture, Food Systems, and Community Development ISSN: 2152-0801 online

www.AgDevJournal.com

h. Would you like help creating written policies?

- Yes

- No

- N/A, I already have written policies

Optional Information

What is the name of the farm about which you are responding?

Name of Person(s) Responding: 